\title{
A experiência de jovens estudantes do Pré- Vestibular Comunitário do Centro de Estudos e Ações Solidárias da Maré (CEASM): entre as marcas do colonialismo e a pedagogia decolonial
}

\author{
Humberto Salustriano da Silva ${ }^{1}$ \\ Francisco Overlande Manço de Souza²
}

\begin{abstract}
Resumo
O artigo trata da experiência de Jovens Estudantes do Pré-Vestibular Comunitário do Centro de Estudos e Ações Solidárias da Maré (CEASM), considerando como tema central para a análise dessa experiência as marcas do colonialismo presentes nas trajetórias de jovens periféricos, assim como suas percepções no que se refere às pedagogias críticas decoloniais praticadas no âmbito de uma educação popular. É sob esta perspectiva que tentamos identificar as marcas colonialistas e as lacunas de formação que caracterizaram as trajetórias dos estudantes que frequentam o pré-vestibular do CEASM, confrontando-as com as pedagogias críticas oferecidas no curso popular.
\end{abstract}

\section{Palavras-Chave}

Trajetórias; Juventude; Colonialismo; Decolonialidade; Educação Popular.

The Experience of Young Students in the Community Pre-University Entrance Examination at the Center for Studies and Solidarity Actions of Maré (CEASM): Between the Marks of Colonialism and Decolonial Pedagogy

\begin{abstract}
The article deals with the experience of Young Students of the Community Pre-University Entrance Examination at the Center for Studies and Solidarity Actions of Maré (CEASM), considering as central theme for the analysis of this experience as marks of colonialism present in the trajectories of peripheral young people, as well as their perceptions with regard to critical decolonial pedagogies practiced in the context of popular education. It is from this perspective that we try to identify as colonialist marks and as training gaps that characterized as trajectories of students who attend the CEASM pre-university entrance exam, confronting them with critical critical pedagogies in the popular course.
\end{abstract}




\section{Keywords}

Trajectories, Youth, Colonialism, Decoloniality, Popular Education.

Artigo recebido: novembro de 2020

Artigo aprovado: dezembro de 2020

Este artigo é fruto direto de nossa experiência como educadores populares em espaços não formais e de uma pesquisa sociológica empreendida por um dos autores que resultou numa tese de doutorado no campo da educação, centrado especificamente em analisar a experiência de jovens estudantes de um pré-vestibular comunitário, no conjunto de favelas da Maré, na cidade do Rio de Janeiro. Nessa perspectiva, o objetivo aqui consiste em apresentar uma pequena parte dessas análises cujo tema central diz respeito às marcas do colonialismo presentes nas trajetórias de jovens periféricos, assim como suas percepções no que se refere às pedagogias críticas decoloniais praticadas no âmbito de uma educação popular. O referido curso chamado de Centro de Estudos e Ações Solidárias da Maré - CEASM - está localizado no Conjunto de Favelas da Maré e atua na região desde 1998 com o objetivo de oferecer aos moradores, um preparatório para o ingresso no ensino superior pautado nos pressupostos de um conhecimento crítico. A educação libertadora de Paulo Freire (1987) e a pedagogia crítico-social dos conteúdos de Dermeval Saviani (1983) e José Carlos Libâneo (1985) constituem os pilares teóricos do CEASM que desde a sua fundação, até os dias atuais já contribuiu para a inserção de centenas de jovens, nas mais diversas universidades públicas da cidade. A análise dessas trajetórias construiu-se à luz teórica dos estudos da sociologia da educação, centrados em obras de inúmeros pensadores como Pierre Bourdieu, Bernard Lahire e Nadir Zago. A partir da leitura desses autores buscamos identificar as peculiaridades de cada percurso escolar, compreendendo os mecanismos de sua constituição, bem como as relações com a escola, a família e outras instituições sociais. 
Além disso, analisamos os percalços dessas trajetórias no âmbito da segregação urbana praticada nas favelas da Maré, investigando os diversos aspectos educacionais associados a essa condição. Somam-se a isso também, o uso de vários outros autores da perspectiva dos estudos decoloniais ${ }^{3}$ que nos auxiliaram a entender de que maneira essas trajetórias juvenis são marcadas pela socialização de um currículo pedagógico colonialista.

É a partir dessa perspectiva que tentamos identificar as marcas colonialistas e as lacunas de formação que caracterizaram esses percursos biográficos, confrontando-as com as pedagogias críticas oferecidas no curso popular. A metodologia para a realização desta pesquisa está pautada em técnicas quantitativas e qualitativas que registraram características dessas trajetórias sociais, oferecendo tanto um suporte para nossas análises teóricas, quanto também um panorama geral das biografias estudantis que circulam ano após ano no pré-vestibular comunitário do CEASM.

\section{Sobre a História do Centro de Estudos e Ações Solidárias da Maré (CEASM) e o seu Pré-Vestibular Comunitário}

A história de fundação do CEASM que começa com a criação de um projeto de pré-vestibular comunitário, surge dentro de um contexto histórico no final dos anos 90, onde a luta pela democratização do ensino superior se intensifıcava através do crescimento de cursos preparatórios populares e da militância em prol das políticas de ação afırmativa. A iniciativa começou quando um grupo de moradores e ex-moradores da Maré decidiu utilizar suas experiências de militância para pensar numa forma de intervenção educacional que de alguma maneira pudesse contribuir para melhorar os índices da educação local.

Dentro desse panorama, a experiência militante do grupo de moradores e ex-moradores da Maré se mostrou essencial para tentar suprir parte dessa demanda, organizando uma rede de educação como o CEASM que passou a atuar em diversas frentes no campo do ensino. Os 
fundadores dessa instituição tinham em comum, o fato de já terem atuado em projetos sociais ligados a Igreja Católica e, mais especificamente, em ações alinhadas com a chamada teologia da libertação. Tinham também ligações políticas com o Partido dos Trabalhadores, através de agremiações locais, além de alguns deles terem participado ativamente da militância na Maré, assumindo postos de liderança nas associações de moradores. A criação do CEASM, portanto, consistiu numa tentativa de agregar todas essas experiências pregressas se inserindo num quadro de luta pela democratização do ensino e acesso a uma educação qualificada nos diversos níveis de escolarização. (SANTOS: 2007).

Nesse sentido, o CEASM começou o ano de 1998 com o seu primeiro projeto educacional de pré-vestibular comunitário, (não por acaso) nos fundos de uma Igreja Católica. Alguns meses depois, se transferiu para um espaço cedido pela Associação de Moradores do Morro do Timbau, onde funciona até os dias de hoje, as inúmeras atividades do projeto. Pouco tempo depois, os fundadores do CEASM também produziram uma carta de princípios onde expressaram os pilares teóricos que deveriam orientar as práticas da instituição, deixando evidente que os objetivos dessa ação pedagógica estavam muito além de simplesmente atuar por uma maior escolarização no bairro. A finalidade também consistia em produzir uma educação crítica entre os moradores, promovendo uma consciência de cidadania e a construção de pensamentos autônomos, estimulando o desejo de transformação da sociedade.

\section{Sobre o Cenário Social Urbano Em Que Se Insere o Pré-Vestibular Comunitário do CEASM}

O desenvolvimento deste artigo agrega um elemento fundamental para a construção das análises sociológicas empreendidas aqui, considerando o fato de que é dentro de uma favela, onde estão concentrados os percursos escolares que são objetos dessa reflexão. Isso quer dizer que não é possível entender as trajetórias de estudantes do conjunto de favelas da Maré, sem levar em conta toda a carga histórica 
de formação das favelas no Rio de janeiro, bem como as inúmeras políticas públicas que há muito tempo criminalizam as periferias urbanas. É preciso, nesse sentido, contextualizar todo esse processo de violência física e simbólica. Isso porque, os estigmas relacionados à favela já as acompanha desde os tempos de seu surgimento há pelo menos um século. A segregação urbana que hoje, faz parte da vida dos jovens que estudam e vivem na Maré, por exemplo, é algo que foi construído historicamente, em contraposição a uma ideia de cidade que quase sempre contemplou uma parcela privilegiada da população (SALUSTRIANO DA SILVA: 2010).

A Maré, assim como qualquer outro lugar da cidade, é um bairro caracterizado por sua diversidade econômica, social e cultural. Bem longe do senso comum que costuma classificar um espaço favelado como homogêneo, o conjunto de favelas da Maré tem perfis sociais diversos; práticas culturais de todos os tipos e um grande potencial de geração de renda. O número de empreendimentos comerciais, por exemplo, passa dos três mil estabelecimentos considerando toda a região da Maré, nos mais variados tipos de serviços oferecidos à população ${ }^{4}$.

Entretanto, apesar de toda essa potencialidade positiva, a Maré é um lugar que constantemente sofre com um tratamento discriminatório proveniente do próprio Estado, e mais especialmente, praticado por aqueles que operacionalizam as políticas de segurança pública. Para os moradores, esses são obstáculos que interferem diretamente no cotidiano da vida na favela. Seja, por exemplo, num simples ato de circulação interna para fazer compras ou visitar um parente. Seja na ida (ou volta) diária em direção ao trabalho, casa ou escola. A realidade é que quase sempre o preconceito e a criminalização sofridas por pessoas que moram na Maré têm se traduzido em incursões violentas por parte de agentes do Estado, gerando conflitos e não poucas vezes, a morte de muitos inocentes.

Localizada entre a Linha Vermelha e Avenida Brasil, e próxima à entrada do aeroporto internacional, a militarização constante desse bair- 
ro tornou-se uma finalidade central para o gerenciamento de conflitos que, porventura, tenham o potencial de gerar uma visibilidade negativa para o Estado. Nesse sentido e não por acaso, a Maré foi, por exemplo, uma das localidades escolhidas pelo governo Cabral para abrigar um dos postos do projeto das Unidades de Polícia Pacificadoras (UPPs) ${ }^{5}$ e teve durante 14 meses seu território ocupado pelo exército brasileiro para, supostamente, garantir a viabilidade de tal projeto. Foram quase três mil soldados das mais diversas regiões do país que ocuparam a região a um custo diário de pouco mais de um milhão de reais ${ }^{6}$.

Mas, diferente do que foi divulgado pelos grandes meios de comunicação, a paz prometida pelas forças de segurança pública esteve bem longe de se tornar uma realidade concreta na Maré. O que se viu na verdade foram constantes tiroteios entre soldados do exército e jovens envolvidos com o tráfıco de drogas local, gerando pânico entre os moradores e uma sensação de insegurança crescente. Não foram poucas vezes em que escolas e comércio fecharam suas portas por conta dos conflitos armados na região. Da mesma maneira, o funcionamento do pré-vestibular comunitário do CEASM não ficou imune aos efeitos da ocupação militar por parte do exército. Os embates frequentes contribuíram para a evasão do curso; prejudicaram diretamente as atividades pedagógicas e obrigaram os educadores e educandos a reduzir a carga horária das aulas, no sentido de garantir a volta para casa um pouco mais cedo, evitando assim, pôr em risco a integridade física dos estudantes.

Portanto, é esse o panorama que caracteriza o contexto de segregação urbana no qual estão submetidas a juventude que ingressa no pré-vestibular comunitário da Maré: uma realidade profundamente desigual no tratamento do poder público e com um cotidiano permeado pelo estereótipo da violência. Diante disso, fazemos as seguintes perguntas? De que maneira esse grupo de jovens estudantes se depara com as práticas de uma educação anticolonialista num curso popular que justamente se propõe a desnaturalizar essas desigualdades e a 
desconstruir o olhar subalternizado sobre a própria trajetória e o lugar de moradia? Este trabalho tem exatamente a finalidade de se debruçar sobre as peculiaridades desse processo, observando as suas contradições e seus efeitos sociais, políticos e pedagógicos.

\section{A Colonialidade nas Trajetórias Juvenis dos Estudantes do Pré- Vestibular Comunitário do CEASM}

Quando decidimos estabelecer os caminhos para escrever este trabalho sobre a experiência de jovens estudantes da Maré, compreendemos que era necessário lançar um olhar mais detido sobre as diversas lacunas históricas presentes no interior desses percursos escolares. Mas não são todas as lacunas que evidentemente nos interessa aqui relatar. Apenas aquelas que parecem não ser tão visíveis aos olhos de qualquer pessoa. Aquelas que se impõem na vida escolar dos estudantes através de mecanismos sutis de dominação cultural. Aquelas que mesmo em trajetórias educacionais regulares e sem maiores percalços mostram a força de sua influência na construção subjetiva das suas percepções de mundo. O público estudantil, objeto desta construção analítica, parece representar muito bem esse caso de lacunas históricas aparentemente invisíveis, mas absolutamente poderosas no que tange às suas marcas na formação escolar. Isso porque, não se trata aqui de jovens que abandonaram a escola, ou que passaram por situações extremas de envolvimento com práticas ilícitas. Dentro de uma região de favela pode ser considerado um grupo seleto que conseguiu concluir o ensino médio. Em geral, tiveram algum tipo de referência para prosseguir nos estudos e de acordo com os dados quantitativos coletados em nossa pesquisa, trata-se em sua grande maioria de jovens solteiros que moram com os pais e que não têm filhos. Obviamente, não deixam de ser trajetórias periféricas por conta disso. Afınal de contas, são jovens que também precisaram trabalhar desde cedo. Nem sempre a questão da repetência pôde ser evitada, por exemplo, e muito diferente da juventude pertencente às classes 
média e alta, esta aqui sempre teve que conjugar a preocupação dos estudos com a sobrevivência diária. Mas ainda assim, nas palavras do francês Bernard Lahire (1997), trata-se certamente de "trajetórias improváveis". Mas então a respeito de qual lacuna histórica queremos investigar? Justamente aquela que tem produzido durante muito tempo, subjetividades permeadas de subalternização. Atravessadas pelos sentimentos mais profundos de inferioridade. Construídas sobre as bases de um silenciamento cultural coletivo. E nada mais sintomático de todo esse processo histórico do que as lacunas produzidas pelas marcas do colonialismo. Mas daí o leitor poderia se perguntar: mas o que isso tem a ver com trajetórias juvenis? Qual é a relevância desse tema para compreender percursos educacionais de jovens residentes de uma periferia na cidade do Rio de Janeiro? Num primeiro momento é de fato compreensível que se faça esse tipo de pergunta considerando que num vislumbre analítico inicial não conseguimos perceber as conexões pertinentes entre um assunto e outro. Mas, na medida em que nossas análises passam de uma fase superficial e começam a se aprofundar nas peculiaridades dessas interseções, conseguimos identificar tudo aquilo que nos ajuda a entender melhor esse processo.

Recorrendo à teoria bourdieusiana, não é possível conceber o indivíduo como uma estrutura subjetiva descolada no tempo e espaço sociais. Muito pelo contrário, a formação do ethos de um sujeito carrega consigo uma gama de processos de socialização que reflete diferentes construções históricas de pensamentos culturais o que por sua vez, contribui para a formação de um habitus determinado. Mas não se trata obviamente de determinações mecanicistas. O que defende Bourdieu (2007)) é tão somente uma conjugação entre estruturas sociais que vão se configurando ao longo do tempo através das instituições, e a ação dos indivíduos, que informados pelos seus processos de socialização constroem as suas próprias percepções sobre a sociedade.

Exatamente assim funcionam as estruturas do colonialismo. Constituíram-se historicamente criando seus pilares sociais. Adequaram-se às 
instituições de Estado responsáveis pelos planejamentos educacionais e pedagógicos. Produziram mentalidades culturais associadas a um projeto de dominação colonial. Portanto, não estão deslocadas de contexto histórico, as visões de mundo que, por exemplo, um jovem estudante da favela carrega consigo no seu imaginário. A dificuldade em reconhecer suas raízes étnicas, os sentimentos de subalternidade, a baixa autoestima cultural, tudo isso está entrelaçado às estruturas seculares do colonialismo que, em última instância, exerce peso decisivo na vida dessa pessoa. Não é por acaso que o filósofo Maldonado Torres (2007) destacou que a experiência de dominação dos povos colonizados por europeus não se extinguiu com o fim do colonialismo histórico. Todas as estruturas sociais que aqui permaneceram continuaram permeadas pela visão do colonizador e aquilo a que muitos autores passaram a chamar de colonialidade passou a representar todos os resquícios desse projeto de dominação presentes em todas as instâncias da vida moderna?.

Temos bem presente em nossas lembranças o início das aulas no ano letivo de 2016 que exemplifica muito bem essas marcas da colonialidade na trajetória escolar de muitos jovens do pré-vestibular comunitário. Nas primeiras semanas de atividades no CEASM no referido ano, o contexto político nacional se encontrava em plena ebulição, às vésperas da derrubada do poder da presidenta eleita Dilma Rousseff. O clima de ódio já havia tomado conta desse país e inevitavelmente os espaços de aprendizagem também eram de algum modo influenciados pelo desenrolar dos acontecimentos. Não foi diferente no ambiente pedagógico do pré-vestibular da Maré. Os alunos transpareciam muitas dúvidas, sobretudo o que estava acontecendo no Brasil, e as aulas iniciais das disciplinas de humanas, já geravam um evidente desconforto numa parte dos educandos. Dentro desse contexto, decidimos na condição de educadores não nos furtar do debate e planejar uma grande conversa sobre a conjuntura política nacional. Organizamos, assim, uma aula interdisciplinar feita a muitas mãos, e no pátio do CEASM ficaram acomodados quase cem jovens ávidos em ouvir o que tínhamos a compartilhar. 
Não podemos dizer que foi uma aula tranquila. Eram temas que mexiam diretamente com a sensibilidade política aflorada dentro daquele contexto e, inevitavelmente, o embate de ideias acabou fazendo parte de todo esse evento. Mas não se tratou de um confronto político pautado exatamente pela ideia da tolerância. A raiva estava nitidamente presente na fala de muitos educandos. Quando suas certezas foram questionadas; quando as histórias que sempre lhe contaram pela primeira vez não faziam sentido, ou quando a imagem que faziam de si mesmos passou a ser seriamente abalada. Tudo isso se refletiu nas muitas intervenções que seguiram ao longo da aula, e talvez o momento mais sintomático de toda a tensão que havia se estabelecido tenha sido quando um dos educandos se levantou para falar e bradou com todas as letras: "sou eleitor de Bolsonaro com muito orgulho".

Esse breve relato nos remete a uma série de questões sobre os posicionamentos políticos e subjetivos desses jovens estudantes que podemos analisar, por exemplo, sob a luz teórica de Frantz Fanon. O filósofo martinicano produziu sua obra nos idos dos anos de 1950, dentro do contexto histórico das lutas anticoloniais no continente africano, e discorreu dentre várias temáticas, a respeito dos males do colonialismo sobre a própria estrutura de personalidade de todo colonizado. Fanon (2008) compreendia particularmente a situação do negro (vítima do domínio europeu) como um reflexo potente das estruturas colonialistas, entendendo que as marcas dessa dominação assumiam características extremamente íntimas. Por ter formação na psiquiatria, Fanon se preocupava em identificar, no colonizado, a construção de uma mentalidade subserviente, mas, ao mesmo tempo, não atribuía essa condição a uma questão meramente individual. Ao contrário, em sua visão, o colonizado era fruto de uma estrutura racista e um processo completo de desalienação só seria possível mediante a destruição de todo o arcabouço construído pelo colonizador. Ou seja, o aniquilamento total daquilo que intelectuais como Maldonado Torres (2007) denominou de a Colonialidade do Ser. 
Ainda no contexto histórico dos anos de 1950, outro autor de grande relevância para os estudos do colonialismo produziu uma série de reflexões que também pode nos ajudar a compreender melhor o quadro contemporâneo das estruturas coloniais. "O retrato do colonizado, precedido pelo retrato do colonizador" foi um livro publicado pelo tunisiano Albert Memmi em 1957, e se tornou um clássico da sociologia, sempre revigorado nos contextos atuais de subjugação do Outro. Memmi (1989) (re) constrói em sua obra uma autêntica descrição das características da personalidade do colonizador e também do colonizado que se encontra sob a batuta do seu domínio. São retratos sociais produzidos por esse escritor que possui a evidente marca histórica do seu tempo e da situação dos povos colonizados no continente africano. Por outro lado, o brilhantismo de sua descrição também deixa explícito que o arcabouço colonial é um elemento que pode ser sempre (re) significado em qualquer sociedade contemporânea e que suas categorias de funcionamento podem ser perfeitamente (re) alocadas para diferentes grupos sociais.

Focando especificamente na sua elaboração do colonizado, Albert Memmi divide as suas percepções em exatamente dez partes: 1. O retrato mítico do oprimido, 2. O colonizado e a cidade, 3. A criança colonizada, 4. Os valores-refúgio, 5. A amnésia cultural, 6. A escola do colonizado, 7. O bilinguismo colonial, 8. A situação do escritor, 9. O ser de carência, e 10. As duas respostas do colonizado. Em cada um desses tópicos, o autor constrói uma análise crítica da situação daquelas pessoas que foram obrigadas a viver e crescer sob uma estrutura de dominação europeia, apagando a memória coletiva dos povos subjugados e suprimindo seu futuro baseado na autonomia. Pretendemos destacar aqui, apenas dois desses pontos, fazendo um paralelo social com a conjuntura histórica dos jovens estudantes favelados do pré-vestibular da Maré com a finalidade de identificar algumas convergências importantes que nos ajudam a compreender com mais detalhes a visão de mundo dessa juventude. Certamente, 
porém, não se constitui como nosso objetivo criar aqui uma equação sociológica reducionista que estabelece uma fórmula mágica pra afirmar categoricamente que favelado é igual a colonizado. Obviamente esse não é o intuito dessa análise, visto que as influências de uma estrutura colonialista não podem ser reduzidas apenas a grupos sociais específicos, ou mesmo a uma patologia de ordem individual, como bem afirmou Fanon (2008) em seu clássico Pele Negra Máscaras Brancas. A tarefa, portanto, que nos propomos a realizar consiste em tão somente identificar no contexto histórico do jovem estudante favelado, elementos que nos ajudam a verificar semelhanças, mudanças ou continuidades de um sistema mundo moderno/colonia/ ${ }^{8}$ que continua a produzir e ratificar desigualdades.

O primeiro ponto que destacamos é $O$ retrato mítico do oprimido que na visão de Albert Memmi se constituiu como obra do colonizador justamente para conferir sentido a sua pratica de subjugação do Outro, legitimando as suas arbitrariedades e excluindo o colonizado da sua própria condição humana. Para que isso seja possivel de acontecer é preciso, antes de qualquer coisa, estigmatizar o grupo dos dominados, taxando-os sempre como potenciais suspeitos dos crimes que são praticados na sociedade. A mera suspeição, portanto, justifica que o colonizador promova ações que, segundo ele, servem para prevenir futuras transgressões. E se já se tem o principal suspeito, por que então não o culpabilizar, o julgar e condenar de maneira eficaz? No caso contemporâneo das favelas na cidade do Rio de Janeiro, a estigmatização se tornou justamente uma das peças-chave para se pensar a construção de políticas de segurança pública, voltadas especificamente para um segmento da população. Desse modo, se define, por exemplo, a identidade do favelado no Rio de Janeiro, forjada inicialmente no âmbito dos estereótipos. O favelado violento, perigoso, conivente com o crime e indolente é a imagem construída pela dita cidade formal e que merece ser sempre combatida e exterminada. O favelado real, por sua vez, cresceu ouvindo sobre si mesmo todas essas elaborações sociais. 
Acostumou-se a ver pelos noticiários que os tiroteios na via expressa que "deixava a cidade refém de bandidos" era o mesmo que acontecia na porta da sua casa. Cresceu entendendo que a favela era sim o reduto principal da violência, pois afınal de contas sempre estavam lá, as drogas e as armas que deveriam ser apreendidas. Carregou consigo uma vida inteira de culpa por morar num espaço favelado. Tentou esconder seu endereço dos amigos na escola e no trabalho, tudo pra não ser acusado de ser um potencial criminoso ou no mínimo, uma pessoa complacente com a bandidagem.

Já no que diz respeito às Duas Respostas do Colonizado, na compreensão do escritor tunisiano, podem ser resumidas nas seguintes ações: assimilação ou revolta. Tanto uma quanto outra reflete na visão do autor, o desejo de se livrar da situação colonial que se encontra a pessoa subjugada. No que diz respeito à assimilação, o colonizado busca incorporar os valores do colonizador, pois este the parece um caminho mais fácil para se livrar da sua condição. Ele sabe que os colonizadores possuem tudo o que nunca teve direito de adquirir, e por esse motivo, entende que também precisa assimilar seus modos de vida para que de alguma forma alcance o status cultural das classes dominante.

Nesse processo, o colonizado passa a amar o colonizador e odiar a si mesmo. Admira a cultura estrangeira; sua música, sua língua, comida e costumes de lazer, ao passo em que tenta desesperadamente apagar a sua própria memória e as suas próprias tradições. Mas todo seu esforço na busca pela assimilação acaba sendo inútil, pois não basta apenas, na compreensão de Albert Memmi (1989) dispensar o seu grupo de origem. É preciso também adentrar num outro. E é justamente nesse ponto que o colonizado vê frustradas todas as suas tentativas de se igualar ao grupo dos colonizadores. Ele obtém do grupo que tanto admira e deseja ingressar, apenas uma recusa explícita que o impede de concretizar seu sonho. O colonizador o vê apenas como um "macaco de imitação", incapaz de viver no seu círculo social, pois sempre o lembrará de que suas raízes históricas não podem ser apagadas ou esquecidas. 
Daí surge a revolta, como a segunda alternativa possível para se tentar conseguir, a libertação de sua condição colonial. Os motivos não poderiam ser mais bem sintetizados nas palavras do próprio escritor:

(...) a revolta é a única saída para a situação colonial que não representa uma ilusão, e o colonizado descobre isso cedo ou tarde. Sua condição é absoluta e exige uma solução absoluta, uma ruptura e não um compromisso. Ele foi arrancado de seu passado e bloqueado de seu futuro, suas tradições agonizam e ele perde a esperança de adquirir uma nova cultura, não tem língua, bandeira, técnica, existência nacional ou internacional, direitos ou deveres: não possui nada, não é mais nada, não espera mais nada. Além disso, a solução é cada dia mais urgente, cada dia mais necessariamente mais radical. O mecanismo de aniquilação do colonizado, posto em andamento pelo colonizador, só pode se agravar a cada dia. Quanto mais a opressão aumenta, mais o colonizador precisa de justificação, mais tem que envilecer o colonizado, mais se sente culpado, mais tem se que justificar, etc. Como sair disso, a não ser por meio da ruptura, da explosão, cada dia mais violenta, desse círculo infernal? A situação colonial, por sua própria fatalidade interna chama a revolta. Pois a condição colonial não pode ser organizada; como uma algema, só pode ser quebrada (MEMMI: 1989, p. 169).

Mas o processo de libertação social exige, antes de qualquer coisa, que o colonizado reconquiste a sua dignidade e autonomia. É preciso que ele recuse o colonizador e se livre da imagem acusadora que durante tanto tempo fez parte da sua subjetividade. É necessário, portanto, atacar frontalmente a opressão; recuperar sua identidade cultural e memória coletiva, reativar suas instituições; formar seus intelectuais e se auto afirmar como protagonista de sua própria história. O colonizador, por sua vez, se põe como obstáculo nesse processo de retomada de autonomia dos dominados, mas não encontra êxito na tentativa de barrar a revolta. A obstinação do colonizado pela reconquista da sua liberdade se sobrepõe com a força 
de todos os oprimidos, questionando os pilares do projeto colonial e recriando novas formas de sociedade (MEMMI: 1989).

Vamos nos transportar agora para realidade do jovem favelado do pré-vestibular comunitário, na cidade do Rio de Janeiro do século $X X I$. Ele cresceu tendo que conviver com estigmas que lhe impuseram ao longo de toda a sua trajetória. A escola, nesse sentido, se tornou pra ele uma possiblidade de mudar o seu quadro social. Estudar para ampliar seu grau de instrução e ingressar num mercado de trabalho que o permita ter um salário melhor virou a sua maior obsessão. É com esse objetivo que chegam ao curso popular. Aumentar o seu leque de conhecimento para criar condições financeiras favoráveis, sair da favela e (re) fazer sua vida. O sonho desse jovem favelado que conseguiu prolongar seus estudos se pauta, nessa perspectiva, na tentativa de ascender socialmente. Ele não está interessado em cultivar a produção de uma consciência de classe, ou a prática de uma solidariedade coletiva. Isso porque, acredita na meritocracia como meio de se vencer e conquistar suas metas. Tudo se resume, portanto, ao seu esforço pessoal, pois se chegou ao patamar que desejava foi porque batalhou muito para isso. Mas esse jovem percebe ao longo do tempo que algo Ihe falta nessa caminhada. Ele não teve todas as oportunidades que gostaria de ter tido acesso. Faltou em sua escola alguns conteúdos fundamentais; a condição financeira de sua família o obrigou a arrumar um trabalho precário para garantir a sobrevivência, e nem sempre o seu direito de ir e vir estava resguardado no lugar de moradia onde estabeleceu as suas raízes. Percebeu também com o tempo que o seu esforço tinha que ser quase sempre maior do que poderia suportar, mas mesmo assim, nem sempre o resultado desejado era o mesmo que se conseguia garantir.

Dentro desse panorama, este jovem favelado, passa a conviver com duas opções básicas: aquela pela qual ele aprende a se resignar ao longo da vida, aceitando os obstáculos que lhes são impostos como meros percalços do destino. E aquela outra na qual ele tenta subverter a ordem das 
coisas, buscando alternativas no papel de um cidadão que tem ciência dos seus direitos diante do Estado, dentro de uma perspectiva muito mais solidária. Ambas as alternativas fazem parte da trajetória de cada um desses jovens favelados na qual uma ou outra vai se sobressaindo de acordo com as escolhas que vão sendo tomadas ao longo de suas vidas.

A experiência educacional do pré-vestibular do CEASM não tem nenhum mérito, nesse sentido, em criar o sentimento de resignação ou mesmo o da revolta nas práticas pedagógicas da sala de aula. Isso porque, elas sempre estiveram presentes ao longo de suas trajetórias biográfıcas. O contato com a educação decolonial se constitui apenas como uma espécie de gatilho, que dependendo da subjetividade de cada um dos jovens educandos, ajuda a alimentar uma ou outra percepção. Como respondeu um dos estudantes do pré-vestibular: "fazer parte do curso apenas confirmou todas as coisas que já mais ou menos pensava. Apenas não tinha o conhecimento suficiente pra saber elaborar tudo isso."

Nessa perspectiva, também se torna importante ressaltar que nenhuma estrutura de dominação apresenta características de alcance absoluto na vida das pessoas. As críticas do historiador marxista E. P. Thompson ao também marxista Louis Althusser já se mostravam bastante lúcidas lá nos idos dos anos de 1970, quando foram publicadas pela primeira vez, através do livro "A Miséria da Teoria ou um planetário de erros". Na visão do historiador inglês E. P. Thompson (1978), o estruturalismo althusseriano conferia uma interpretação da teoria marxista que suprimia totalmente a ação real do indivíduo. As forças opressoras do estado, nesse sentido, exerciam um poder imperial sobre a sociedade, fechando completamente as possibilidades de protagonismo dos sujeitos inseridos nessa engrenagem de poder. A própria luta de classes, na perspectiva de Althusser se tornava muito mais uma elucubração teórica com uma classe de trabalhadores conceituados por intelectuais, do que propriamente uma luta protagonizada por personagens da vida real. Nesse sentido, o que E. P. Thompson faz questão de destacar é que toda estrutura de dominação sempre 
será ameaçada pelo seu elemento mais desestabilizador: a experiência humana. Assim aconteceu em todas as partes do mundo, e assim também aconteceu e ainda acontece, no sistema capitalista moderno/ colonial. A criatividade humana sempre esteve presente dentro das instituições pelas quais o Estado buscou exercer o seu poder.

Apenas se as estruturas de dominação exercessem um poder absoluto teríamos um modelo de juventude pobre marcado pela total resignação, submissão e falta de esperanças. Mas é justamente a capacidade humana de se (re) inventar nas adversidades e de resistir nas experiências práticas da vida, que impedem que esse tipo de tragédia possa acontecer.

\section{Os Efeitos de uma Pedagogia Decolonial no Pré-Vestibular Comunitário do CEASM}

Considerando, portanto, essas inúmeras possibilidades de se romper com a estrutura do colonialismo é que podemos, por exemplo, nos debruçar em experiências de uma pedagogia crítica que tem exatamente a finalidade de desconstruir os pilares do arcabouço colonial presente na educação. Nesse ponto, a experiência dos jovens estudantes do pré-vestibular comunitário do CEASM com os processos de uma aprendizagem decolonial influenciaram de maneira decisiva nas muitas visões de mundo que se moldaram ao longo do tempo. Seja confirmando os posicionamentos políticos que já faziam parte da sua formação. Seja criando ou ampliando novas percepções de mundo a respeito das inúmeras temáticas que são tratadas ao longo do ano letivo.

Aqui, vale destacar algumas características da pedagogia decolonial do pré-vestibular do CEASM que de um modo geral está pautada basicamente, naquilo que Vera Candau (2003) denominou de ancoragem social dos conteúdos. Ou seja, a tentativa de (re) significar o conhecimento profundamente eurocentrado e apresentado sob o manto da neutralidade científica, contextualizando historicamente a sua produção e identificando os sujeitos sociais imersos nesse processo. 
Essa metodologia de aprendizagem parte, portanto, do pressuposto de que o ensino que costumamos absorver no espaço escolar se constitui como um reflexo do conceito de modernidade / colonialidade que trabalha o conhecimento, sempre como um elemento universal, homogêneo e supostamente amparados em bases científicas. Não há nesse sentido o espaço para o questionamento; nem o diálogo entre saberes distintos, e nem um ambiente pedagógico construído com base no convívio das diferenças. Numa tentativa então de contrapor essa forma de transmissão de conteúdos acríticos, o pré-vestibular do CEASM adota na prática aquilo que a pesquisadora Catherine Wash (2013) conceituou de interculturalidade crítica. Uma didática decolonial do conhecimento que manifesta a pretensão de potencializar as culturas historicamente silenciadas, promovendo uma aprendizagem crítica que recupera o protagonismo dos povos subalternizados e colonizados ao longo dos séculos. Nas palavras da pesquisadora Vera Candau:

Trata-se de questionar as diferenças e desigualdades construídas ao longo da história entre grupos socioculturais étnico-raciais, de gênero, orientação sexual, entre outros. Parte-se da afırmação de que a interculturalidade aponta à construção de sociedades que assumam as diferenças como constitutivas da democracia e sejam capazes de construir relações novas, verdadeiramente igualitárias entre os diferentes grupos socioculturais, o que supõe empoderar aqueles que foram historicamente inferiorizados. (CANDAU: 2014, p. 28).

Não por acaso, ao longo de todo o ano letivo, os educadores do CEASM se empenham justamente em fortalecer o diálogo com as diferenças, abordando temáticas pedagógicas que privilegiam as identidades diversas. Além disso, a pedagogia decolonial do espaço também (re) visita temas históricos fundamentais que ajudam na construção de uma consciência crítica numa perspectiva de classes, criando sentimentos de solidariedade e percepções coletivas de transformação. 
Dentro desse contexto, a ancoragem histórico-crítica social dos conteúdos se materializa todos os anos em grandes aulas que abordam temas como: a construção histórica do racismo no Brasil e no Mundo; a luta dos trabalhadores em processos de industrialização; a luta das mulheres no contexto nacional e internacional; a formação do centro histórico do Rio de janeiro; processos das lutas sociais na América Latina; Ditadura Civil-Militar no Brasil e suas consequências; religião e diversidade de gênero. Todas essas aulas constituem-se na base central da decolonialidade do espaço do pré-vestibular do CEASM e sempre geram grandes debates e discussões ao longo do ano que ajudam nos processos de formação dos estudantes.

Atualmente, no blog do CPV existe um espaço na qual alguns educandos manifestam suas opiniões a respeito de cada uma dessas iniciativas, indicando os efeitos que foram produzidos na vida pessoal de cada um deles. Sobre um “aulão”, por exemplo, a respeito do dia internacional da mulher, uma educanda relatou:

Na semana desse dia, o curso pré-vestibular do CEASM abordou a temática da mulher de alguma forma em todas as aulas. A mulher na ciência, na história e no mundo. Cada aula com seu propósito de nos fazer entender como a mulher é importante dos processos mais simples aos mais complexos. Eu, como mulher e aluna, achei incrivel passar por essa experiência de entender e saber meu lugar e como me colocar em certas situações. Eu descobri alguns tipos de violência que nem sabia que existiam, consegui também com isso saber onde recorrer e quem procurar nesses casos. Vi que a violência e a desvalorização da mulher vêm de muitos anos atrás, com o crescimento da nossa sociedade patriarcal. Nós sermos tratadas como somos é fruto de um machismo quem vem sendo estruturado desde a colonização. Ver o quanto, infelizmente, isso ainda é presente hoje é triste. Porém, com as aulas foi possível o entendimento de que tudo isso é histórico e com isso, vi que ainda temos esperança de pelo menos tentar mudar para o nosso futuro (Relato de aluna do CPV) ${ }^{9}$. 
Portanto uma experiência que contou com um (re) posicionamento histórico a respeito da luta das mulheres na sociedade, na qual se apresentou os processos de luta ao longo do tempo e a constituição secular dos pilares do patriarcado e do machismo. A referida estudante relatou, assim, o seu encontro com uma nova perspectiva de conhecimento, reativando as suas esperanças para a construção de um futuro melhor. Grande parte desses efeitos também foram sentidos pelos estudantes entrevistados para nossa pesquisa, nos mais diversos âmbitos pedagógicos. Mas o resultado que mais se destacou em todos eles, se apresentou na relação social que estabeleceram com o seu espaço de moradia, - a favela. A maioria afırmou que a experiência de aprendizagem vivenciada no CEASM exerceu um papel significativo na construção de suas identidades em relação ao espaço favelado. Existia, nesse sentido, um sentimento de baixa autoestima e vergonha que impedia que esses educandos se reconhecessem como moradores de favela por temerem o que poderia vir depois, como manifestações de preconceito e humilhação no cotidiano do seu trabalho, escola ou relacionamentos. Mas, na medida em que passaram a compreender melhor a constituição histórica das lutas sociais nos espaços de favela, disseram que também começaram um processo gradativo de auto aceitação e de afırmação de uma identidade periférica que valorizava, justamente, a capacidade de luta dos trabalhadores favelados. Defınitivamente, não se trata de uma mudança que possa ser minimizada nesse processo decolonial de aprendizagem no curso pré-vestibular do CEASM. Ela remete a uma verdadeira reconstrução de uma subjetividade subalternizada ao longo da vida e que, em vários aspectos, conseguiu superar a desumanização imposta pelas estruturas de caráter colonialista. A colonialidade do ser, nessa perspectiva, perde uma das suas dimensões essenciais de existência para dar lugar a uma nova concepção de mundo, marcada pela altivez de uma cultura historicamente inferiorizada e pela força de sua resistência em contextos de contínua opressão. 


\section{Referências}

BOURDIEU, Pierre. O Poder Simbólico. Rio de Janeiro. Ed. Bertrand Brasil. $11^{\mathrm{a}}$ ed, 2007.

CANDAU, Vera. Educação Intercultural: Entre Afırmações e Desafıos. In: Currículos, Disciplinas Escolares e Culturas. MOREIRA, Antônio Flavio Moreira \& CANDAU, Vera. Petrópolis. Vozes. 2014.

FANON, Frantz. Pele Negra. Máscaras Brancas. Edufba. Salvador. 2008.

FREIRE, Paulo. A Pedagogia do Oprimido. Rio de Janeiro. Paz e Terra. 17 ed, 1987.

LAHIRE, Bernard. Sucesso Escolar nos Meios Populares. As Razões do Improvável. São Paulo. Ática. 1997.

LANDER, Edgardo. Ciências Sociais: Saberes Coloniais e Eurocêntricos. In: A Colonialidade do Saber: Eurocentrismo e Ciências Sociais. Perspectivas Latino-Americanas. LANDER, Edgardo. (org). Coleccion Sur, CLACSO, Ciudad Autonoma de Buenos Aires, Argentina. Setembro, 2005.

LIBÂNEO, José C. Democratização da escola pública: a pedagogia crítico-social dos conteúdos. São Paulo: Loyola, 2008 (24ª. Ed.). 1ª. Edição. 1985.

MEMMI, Albert. O Retrato do Colonizado, Precedido do Retrato do Colonizador. Rio de Janeiro, Ed. Paz e Terra. 1989.

MICNOLO, Walter, D. A Colonialidade de Cabo a Rabo: O Hemisfério Ocidental no Horizonte Conceitual da Modernidade. In: A Colonialidade do Saber: Eurocentrismo e Ciências Sociais. Perspectivas Latino-Americanas. Colleccion Sur, Sur - CLACSO. Ciudad Autonoma, Buenos Aires. 2005.

MOREIRA, A.F.B. \& CANDAU, V. M. Educação Escolar e Cultura(s). Construindo Caminhos. Revista Brasileira de Educação. Maio|Jun|Jul|Agos|, 2003.

QUIJANO, Aníbal. Colonialidade do Poder, Eurocentrismo e América Latina. In: A Colonialidade do Saber: Eurocentrismo e Ciências Sociais. Perspectivas Latino-Americanas. LANDER, Edgardo. (org). Coleccion Sur, CLACSO, Ciudad Autonoma de Buenos Aires, Argentina. Setembro, 2005.

SALUSTRIANO DA SILVA, Humberto. A Remoção (Re) Pautada na Cidade do Rio de Janeiro. Discursos, Mídias e Resistências - 2005 a 2010. Dissertação de Mestrado. Instituto de Pesquisa e Planejamento Urbano - IPPUR. Universidade Federal do Rio de Janeiro. 2010. 
SANTOS, Sérgio Baptista dos. O Sentido político do pré-vestibular comunitário da Maré: adesões e resistências. Dissertação de Mestrado. Universidade Estadual do Rio de Janeiro - UERJ, 2007.

SAVIANI, Dermeval. Escola e democracia. Campinas: Autores Associados, 2008 (39ª Ed.). 1a. edição: 1983.

THOMPSON. E. P. A Miséria da Teoria ou um Planetário de Erros. Uma Crítica ao Pensamento de Althusser. Ed. Zahar. 1978.

TORRES, Nelson Maldonado. Sobre la Colonialidad del Ser. Contribuciones al desarollo de um concepto. In: El Giro Decolonial - Reflexiones para uma Diversidad Epistémica más allá del Capitalismo Global. GOMES, Santiago Castro; GROSFOGUEL, Ramón. (org). Pontifícia Universidad Javeriana-Instituto Pensar. Universidad Central IESCO. Siglo del Hombre Editores. 2007.

WASH, Catherine. Pedagogías Decoloniales. Práticas Insurgentes de resistir, (re) existir, y (re) vivir. Tomo eu, Quito. Abya-Yala. 2013.

ZACO, Nadir. Cursos Pré-Vestibulares Populares. Limites e Perspectivas. Perspectiva, Florianópolis, v. 26, n. 1, 149-174, jan./jun. 2008.

\section{Notas}

1 Doutor em Educação pela Universidade Federal do Estado do Rio de Janeiro - UNIRIO. Mestre em Planejamento Urbano e Regional pela Universidade Federal do Rio de Janeiro - UFRJ, Pesquisador NEPS-CEASM Brasil, https://orcid. org/0000-0001-5035-5510, humbertosalustriano@gmail.com.

2 Professor da rede pública de ensino do Estado do Rio de Janeiro (SEEDUC-RJ), Pesquisador NEPS-CEASM Brasil. https://orcid.org/0000-0001-8559-5135, franciscooverlande@gmail.com

3 Os autores que referenciam este trabalho no que diz respeito aos estudos decoloniais são aqueles que fazem parte de um grupo de intelectuais que tem se debruçado sobre essa perspectiva, no sentido de compreender as características essenciais do que chamam de modernidade / Colonialidade e que moldam as relações de dominação no mundo contemporâneo. Autores como Catherine Wash (2013), Walter Mignolo (2005), Anibal Quijano (2005), Maldonado Torres (2007) e Edgardo Lander (2005) serviram de base para esta produção.

4 Esses dados fazem parte de uma pesquisa realizada pelo Observatório de Favelas e Redes da Maré sobre os empreendimentos locais e publicado em livro no ano de 2014.

5 Para saber mais sobre os projetos das UPPs, ver o trabalho de dissertação de mestrado de Marielle Franco (2014) na qual ela destrincha a política de segurança pública no Estado do Rio de Janeiro. 
6 O valor gasto com a ocupação militar no conjunto de favelas da Maré foi revelado no Diário Oficial da União com a publicação de uma Medida Provisória, autorizando um crédito de $\mathrm{R} \$ 200$ milhões de reais para a aplicação específica no apoio logístico às forças de segurança pública. (Jornal O Globo, 26/06/2014).

7 De acordo com os intelectuais que estudam o estado moderno / colonial, a experiência histórica do colonialismo deixou marcas estruturais nas sociedades dominadas, mesmo após se tornarem estados independentes. Tais resquícios são identificados pelo conceito de colonialidade que estão caracterizados sob três formas de existência: a colonialidade do poder, a colonialidade do saber e a colonialidade do ser. Todas elas pautadas na anulação do ser colonizado nas suas diversas formas de existir. (LANDER:2005; QUIJANO: 2005; TORRES: 2007)

8 O Sistema Mundo - Moderno/Colonial, segundo Walter Mignolo (2005) diz respeito a experiência moderna de dominação que se constituiu no século XVI, na medida em que as estruturas coloniais transcenderam as fronteiras da Europa. A partir daí, se criou de acordo com esse autor relações assimétricas de poder no que diz respeito aos povos dominados, na medida em que foram silenciados e subalternizados na constituição da própria existência.

9 É possivel acessar esse relato e de outros estudantes no blog do pré-vestibular do CEASM. http://cpvceasm.wordpress.com 


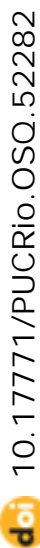

